\title{
Phase Transformation on Interface between NiCoCrAlY Bond Coat and Substrate and Study of Thermal Barrier Coating as High Temperature Material
}

\author{
H. Purwaningsih ${ }^{1}$, L. Noerochim ${ }^{1}$, R. Fajarain ${ }^{1}$, J.A. Hakim ${ }^{1}$, and Sulistijono ${ }^{1}$
}

\begin{abstract}
Thermal Barrier Coating material consists of Yttria stabilized zirconia (YSZ) as a top coat and bond coat NiCoCrAIY. It is used to protect NiCoCrAlY super alloys for high temperature applications due to its corrosion resistant properties and resistance to thermal fatigue. In the present study, top coat and bond coat were deposited on the substrate using plasma spraying process, followed by thermal fatigue treatment, by heating up to $900{ }^{\circ} \mathrm{C}$ for 5 hours and cooling down to $25^{\circ} \mathrm{C}$ for 15 minutes, this process called one cycle. Thermal fatigue was conducted until the material failure. Electron microscope was used to analysis microstructure of the sample after thermal fatigue and $x$-ray diffraction to analysis phase changed on the interface between bond coat and substrate. The result showed that the specimens failed at 42 cycles (210 hours). A new phase identified as $\mathrm{Ni}_{3} \mathrm{Al}$ was formed.
\end{abstract}

Keywords - thermal fatigue, phase transformation, bond coat NiCoCrAIY, substrate NiCoCrAIY

\section{INTRODUCTION}

The use of super alloys for applications at high temperatures has been long known in the industry and transportation. Especially for nickel-based super alloy, nickel super alloy has high corrosion and oxidation resistance. For the high temperature applications, it has been developed the thermal barrier coating. The coating system consists of ceramic top coat and bond coat. The top layer of ceramic works as heat resistance and bond coat serves as a protective substrate from attacks by oxygen and the decrease in the coefficient of thermal expansion between ceramic and substrate. Previous study suggested that the coating layer were easily to be failure, this failure caused by growth rate, morphology, microstructure and adhesives of aluminum oxide that is formed on the bond coat layer [1].

Thermal barrier coating (TBC) of ceramic top-coats made from $\mathrm{Y}_{2} \mathrm{O}_{3}$-stabilized $\mathrm{ZrO}_{2}$ (YSZ) have been used successfully in gas-turbine engine applications for more than 30 years. YSZ has its favorable performance from a combination of properties that include low thermal conductivity, high thermal expansion coefficient, and phase stability to relatively high temperatures. With advanced engine requirements for improved performance and increased durability, a new generation of thermal barrier coatings is needed to provide greater insulation

${ }^{1}$ H. Purwaningsih, L. Noerochim, R. Fajarain, J.A. Hakim, and Sulistijono are with Department of Material and Metallurgy Engineering, FTI, Institut Teknologi Sepuluh Nopember, Surabaya, 60111, Indonesia. E-mail: hariyati@mat-eng.its.ac.id. (lower thermal conductivity) and permit higher operating temperatures [2].

Thermal barrier coating system has been widely used to protect the gas turbine engine components and engine power plant against heat and fluctuating environments. This system serves to reduce the temperature of the metal substrate and improve corrosion and oxidation resistance thus enhancing the efficiency of machines and extending the life of the components. Thermal barrier coatings provide an advantage for increasing inlet gas temperature without raising the surface metal temperature. Typical turbine blade coatings comprise a metal surface layer modified to generate a protective layer of aluminum oxide in service and an outer thermal barrier (usually porous yttria stabilized ceramic). They are approximately 150 microns thick. The coatings eventually fail mechanically in thermal cycling due to stresses generated by thermal expansion differences between the layers and growing layer of oxide metal [3].

In the present study, it was focused on analyzing the bond coat materials sprayed on metal base NiCoCrAlY, and followed by thermal fatigue analysis. The objective of the research was to study the microstructure evolution and phase changed on the interface bond coat and substrate NiCoCrAlY alloy.

\section{METHOD}

The material studied was NiCoCrAlY alloy substrate taken from gas turbine blade for high temperature operation, while the bond coat layer used Merck NiCoCrAlY powder. For top coat layer yttria stabilized zirconia powder (YSZ) was selected. Flame spraying coating process used Thermo Spray Gun Type 5P-II, where the NiCoCrAlY substrate material was squareshaped, lined with two layers for the outer layer (top coat) of YSZ ceramics, the middle layer was the adhesive bond coat consisting of the powder NiCoCrAlY. Flame spraying was used in this study, where the material selected as coating material coating was in the form of powder, using acetylene gas fuel and oxygen to melt the powder material for covering the base metal.

Thermal fatigue experiment includes high temperature treatment in the furnace at $900{ }^{\circ} \mathrm{C}$ for 5 hours and then cooling at room temperature for 15 minutes, this was conducted for one cycle. Material characterization was done including $\mathrm{x}$-ray diffraction (XRD) with Phillips MPD System to identify phase changes that occur during the process of thermal fatigue, while an electron microscope (JEOL SEM / EDX) was used to observe changes in the microstructure and identify the changes in the composition of the elements in the region interface. 


\section{RESULT AND DISCUSSION}

\section{A. Macrostructure Analysis on Specimen}

Macrostructure analysis was performed on specimens without treatment and the specimens heated at $900{ }^{\circ} \mathrm{C}$ for 200 hours. Specimen shown in Fig. 1.a is still in good condition, with a ceramic layer covering the surface of a perfect specimen. This condition is obtained after the specimens coated by plasma spraying process. After the cycling thermal treatment process carried out at $900{ }^{\circ} \mathrm{C}$, the specimens experienced physical changes gradually. In the first two cycles (one cycle is 5 hours of heating), the specimens have patches - black spot on its surface, as shown in Fig. 1.b, but it is still not showing defects or cracks. Defect is not found because the oxides on the surface of the top coat protected top coat surface from the burning surface due to heating. After five cycles, it had been shown cracks in the specimen, Fig. 1.c thermal barrier coating starts to fail when cracks occur, for topcoat thickness is less than $250 \mu \mathrm{m}$ will lead to local separation at the region near the bond coat. This crack started at the corner of the specimen. The phenomenon of breakdown of the corners of the specimen can be explained because the corner is a section with the highest stress concentration. This is because of stress concentration in the specimen as a resulting the existence of residual stress. In TBC of ceramic coating, there are different variations of residual stress in each layer. The source of this residual stress is from the coating process itself, such as rapid cooling, solidification, thermal contraction and recovery of micro cracks due to stress, the differences in thermal coefficient of heat on the ceramic and bond coat.

These cracks occur only locally at first, but with increasing cycles, crack is getting wider and growing to another area of specimen. Because the thickness of the topcoat more than $250 \mu \mathrm{m}$, the crack will occur in ceramics, above the interface between the ceramic bond coat, which agrees with research conducted by another researcher [4]. As shown in Fig. 1.d, there are two areas widened cracks in the specimen for 42 cycles. TGO residual stress, surface roughness, decreased concentration and fatigue of aluminum bond coat layer has an important role in the process of $\mathrm{TBC}$ failure.

\section{B. Electron Microscope Analysis (SEM/EDX)}

Based on Scanning Electron Microscope (SEM) analysis as shown in Fig. 2.a, the specimens without treatment have a thickness of $320 \mu \mathrm{m}$ in top coat and bond coat of $120 \mu \mathrm{m}$. While shown in Fig. 2.b, the thickness of the specimen with a top coat is $300 \mu \mathrm{m}$ and bond coat of $120 \mu \mathrm{m}$. At $100 \mathrm{x}$ magnification, the changes can be observed that a depletion layer of top coat is $10 \mu \mathrm{m}$. This can be explained that when the system TBC (thermal barrier coating) in the heating treatment up to at above $900{ }^{\circ} \mathrm{C}$, then there will be physical changes to each layer. Top layer (top coat) is made by powder $8 \%$ yttria stabilized zirconia receiving the greatest heat load from the other layers. Despite having a low thermal conductivity around $2.5 \mathrm{~W} / \mathrm{mK}$, but with a continuous and cyclic heating the ceramic surface will experience expansion and contraction during thermal cycle process. This process is caused that surface of the ceramic thickness is reduced from the initial conditions.
In Fig. 3 specimen with a magnification of 500 times, it can be seen some parts which is oxidized, primarily at the interface between the bond coats to the substrate. Bond coat powder is the first superimposed on the substrate before coating top coat, although composition of alloy generally similar to the substrate, but the powders formed allows the trapped air during the coating process. When the plasma spraying done, powder coated surface were melted, effect of high temperature operation of blower.

By this process the bond coat powder can be attached to the substrate. Hot air trapped due to plasma spraying resulted in porosity on interface bond coat-substrate. Oxidation of elements on bond coat and substrate are also important factor to the formation of black points along with the interface between the bond coats to substrate. But in general, viscosity is generated based on the images that are good enough because not all parts of the interface are porosity, some sections showed good adhesiveness.

By performing on specimens' heat treatment, Fig. 4 shows the interface between the bond coat and substrates that have a finer texture. Oxides arising relatively few and showed a good viscosity, and is also seen that there is no porosity on the interface between the bond coat/ substrate. Grooves are formed at the interface bond coat/substrate coating process, a little bumpy due to bond coat by plasma spraying. In the plasma spraying process, before the bond coat layer superimposed on the material, it is preceded by the coorving surface with sand blasting to enhance and expand the surface roughness which later formed the bond between the substrate with the bond coat [5], that the surface of the substrate which in smoothening provides a better resistance than the oxide surface that is not given the treatment does., This is because of $\alpha-\mathrm{Al}_{2} \mathrm{O}_{3}$ oxide that is merely produced.

Observations on the interface area showed the elongated bright colors. This is the result of diffusion layer during the oxidation process takes place so that resulted in physical changes such as changing the color becomes lighter. Emergence of a new layer between the substrate with a bond coat layer has a thickness of the linear to the length of time of sintering or heating [6]. The report also explains that the new layer has similar characters with $\mathrm{Ni}_{3} \mathrm{Al}$ phase, in terms of total percent composition of alloying elements and violence Vikcers average hardness. When high temperature is applied to the TBC system based on NiCoCrAlY, inter diffusion alloying elements can lead to fail in materials. NiCoCrAlY bond coat layer with high Al content serves as a source of aluminum for the formation of thermally grown oxide (TGO). If there is a depletion of aluminum diffusion to another layer, it is indicating TGO formation by aluminum and oxygen. EDS analysis indicate that the addition of aluminum at the interface is $35.6 \%$, which means a decrease in the same concentration on the formation of TGO.

Shown in Fig. 4 it was found that light and dark phase dominates the overall image. Dark phase has a relatively wide at $11.1 \%$ and the oxide area of $2.77 \%$. It is not seen any porosity in the Fig. 4 due to the bond coat layer coating process where very little air can be trapped in the bond coat. $\mathrm{Ni}$ has a melting point of $1455{ }^{\circ} \mathrm{C}$, while the melting point of $\mathrm{Co}, \mathrm{Cr}, \mathrm{Al}, \mathrm{Y}$ are respectively $1495{ }^{\circ} \mathrm{C}$, 
$1907{ }^{\circ} \mathrm{C}, 660{ }^{\circ} \mathrm{C}$ and $1526{ }^{\circ} \mathrm{C}$. Aluminum has a melting point below the temperature treatment at $900{ }^{\circ} \mathrm{C}$, which is $600{ }^{\circ} \mathrm{C}$. Aluminum could oxidize at high temperature; therefore the oxidized aluminum has a very high melting point. By heating the specimen to give the energy at each element and react with the surrounding area, Al reacts easily with $\mathrm{Ni}$ producing intermetallic phase $\mathrm{Ni}_{3} \mathrm{Al}$.

SEM/ EDX analysis on some regions (square line) is shown in Fig. 5, and the elements data are tabulated on Table 3.1. It can be seen that major elements observed is Nickel (Ni) with $40.02 \%$ percent of the mass. Other elements based on the percent mass include $\mathrm{Cr}(21.26 \%)$; $\mathrm{Co}(20.04 \%), \mathrm{Fe}(10.62 \%), \mathrm{Mo}(3.67 \%), \mathrm{Al}(3.28 \%)$ and Mn $(1.11 \%)$. But there is an interesting phenomenon in that there is no $\mathrm{ZrO}_{2}$ in the sample, as it has been confirmed by XRD analysis (Fig. 6). The $\mathrm{ZrO}_{2}$ may be found in other area. On the other hand, the presence of $\mathrm{Fe}$ element is greater than the weight percent of $\mathrm{Al}$, in asreceived specimen; however, after oxidize there was not identifying $\mathrm{Fe}$ element. Fe cannot be separated from the alloy even though the amount is less than $1 \%$ on total elements on super alloys, so it is also identified on interface layer before oxidation treatment is applied. After oxidation it cannot identify clearly appearance of ferrous on interface layer, it is suggested that aluminum is diffused from bond coat to interface layer. Table 1 shows an increasing $\% \mathrm{~W}$ of aluminum and a decreasing of ferrous because of diffusion $\mathrm{Al}$ to interface layer.

Based on Table 1 it can be seen the addition of the $\mathrm{Al}$ content at the interface bond coat/ substrate up to $1.19 \%$. Increasing of $\mathrm{Al}$ correspond to alumina forming, on the oxidation $\mathrm{Al}$ react with oxygen to form $\mathrm{Al}_{2} \mathrm{O}_{3}$. This oxide phase has important role as thermally grown oxide layer. Cobalt has decreased significantly by $8.87 \%$, these elements has transported to the other layer correlated to diffusion. Thus the decline of this element on the interface bond coat/substrate results in the diffusion at this interface. Elevated levels of $\mathrm{Ni}$ at the interface of $20.74 \%$ indicate the movement of these elements into the interface bond coat/substrate. The addition of $\mathrm{Ni}$ element at the interface results in suppression of chemical activity of $\mathrm{Al}$ at the interface; it induces disturbing movement towards the surface of alumina bond coat/ topcoat to form the TGO, subsequently acts on material failure. All elements had indicated diffusion process from bond coat to the interface layer and had changed the composition both interface layer and bond coat. As shown in Fig. 4, in the interface layer had formed dark area as thermally grown oxide layer and suggested as $\mathrm{Al}_{2} \mathrm{O}_{3}$. Quadakkers explained that during the heat treatment process of thermal fatigue on the specimen formed a thermal barrier coating system, causing the emergence of thermally grown oxide in the area of interface between top coat and bond coat [8]. This region is the weakest area and the start of the formation of cracks.

\section{A. X-ray Diffraction Analysis}

$\mathrm{X}$-ray diffraction analysis on as received specimen indicated that the dominant phase is $\mathrm{ZrO}_{2}$ and new phase of NiAl. Previous study reported that the same phase $\mathrm{ZrO}_{2}$ was found, but by increasing thermal fatigue cycles zirconia became minor phase followed by phase $\mathrm{Ni}_{3} \mathrm{Al}$ and $\mathrm{Ni}$ base phase [6]. However, in the present study, specimen was prepared by removing the previous upper layer until the interface between the substrate-bond coats obtained, around $400 \mu \mathrm{m}$ from the surface above. Hence $\mathrm{ZrO}_{2}$ remained of the top coat, not present in the interface.

\section{CONCLUSION}

Thermal cyclic influences on phase transformation in the interface layer. Intermetallic phase is found in the interface bond coat and substrate as result of diffusion during thermal cyclic. On the thermal barrier coating system, it is found failure in the interface layer bond coat NiCoCrAlY and substrate of super alloys. It is found porosity and crack along interface layer. Porosity is induced by unhomogenity of bond coat powder when it is spraying on substrate. After thermal cyclic treatment it is found crack propagation. This microstructure failure is induced by significantly difference of coefficient thermal expansion of bond coat and substrate. Thermal cyclic treatment would induce crack propagation worst.

\section{ACKNOWLEDGEMENT}

Author acknowledges to Hibah Strategis Nasional Grant of DIKTI for their support of granting this research. Author also thank very much for all member team who had support and worked very hard for this research.

\section{REFERENCES}

[1] W.J. Quadakkers, V. Shemet, D. Sebold, R. Anton, E. Wessel, L. Singheiser, 2005, "Oxidation characteristics of a platinized MCrAlY bond coat for TBC systems during cyclic oxidation at $1000^{\circ}$ C", Surface \& Coatings Technology, Vol. 199, pp. 77-82.

[2] Padture, Amol D. Jadhav, Nitin P, 2007, "Thermal barrier coatings for gas-turbine engine applications", Science, 296:2002, pp. $280-284$

[3] A. Atkinson, J. Williamson, 2007, "Materials for energy", Materials World, ProQuest Science, pp. 34

[4] S. Bose, dan J. DeMasi-Marcin, 1997, "Thermal barrier coatings experience in gas turbine engines at Pratt \&Whitney", Journal of Thermal Spray Technology, 6(1), pp. 99-104.

[5] J. Ilavsky and J.K. Stalick, Feb 2000, "Phase composition and its changes during annealing of plasma-sprayed YSZ", Surface \& Coatings Technology 127:2000, pp. 121-129.

[6] H.Chen, K. Zhou, Z. Jin, dan C.Liu, 2003, "Diffusion and phase transformation on interface between substrate and NiCrAlY in YPSZ thermal barrier coatings", Journal of Thermal Spray Technology 13(4), pp. 515-520.

[7] A. A Hesnawi, Hefei Li, Zhaohui Zhou, Shengkai Gong, Huibin $\mathrm{Xu}, 2007$, "Effect of Surface Condition during Pre-Oxidation behavior of MCrAlY bond coat prepared by EB-PVD", Surface \& Coatings Technology, 201, pp. 6793-6796.

[8] Hengbei Zhao, 2006, "Morphology and thermal conductivity of ytria-stabilized zirconia coating", Acta Materialia 54(2006). 
IPTEK, The Journal for Technology and Science, Vol. 21, No. 4, November 2010

TABLE 1.

ELEMENTS ANALYSIS ON INTERFACE LAYER USING SEM/EDX

\begin{tabular}{cccc}
\hline Elements & $\begin{array}{c}\text { As-received } \\
(\% \mathrm{~W})\end{array}$ & $\begin{array}{c}\text { Oxidation } \\
(\% \mathrm{~W})\end{array}$ & $\Delta \mathrm{W}$ \\
\hline $\mathrm{Al}$ & 6.74 & 8.93 & +1.19 \\
$\mathrm{Cr}$ & 22.71 & 22.70 & -0.01 \\
$\mathrm{Mn}$ & 1.13 & - & -1.13 \\
$\mathrm{Fe}$ & 10.56 & - & -10.56 \\
$\mathrm{Co}$ & 18.88 & 10.26 & -8.62 \\
$\mathrm{Ni}$ & 37.86 & 56.04 & +18.18 \\
$\mathrm{Mo}$ & 2.12 & - & -2.12 \\
$\mathrm{Ti}$ & - & 2.07 & +2.07 \\
\hline
\end{tabular}

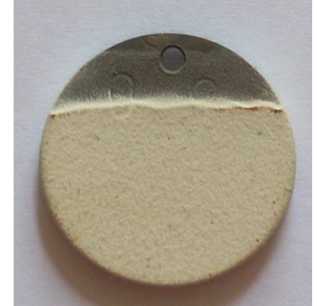

(a)

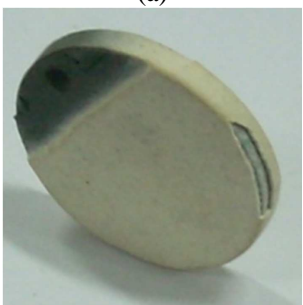

(c)

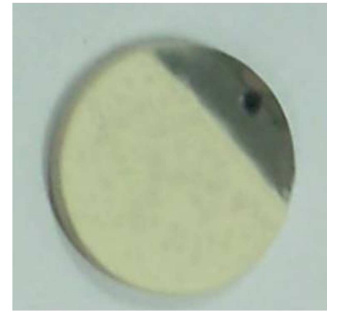

(b)

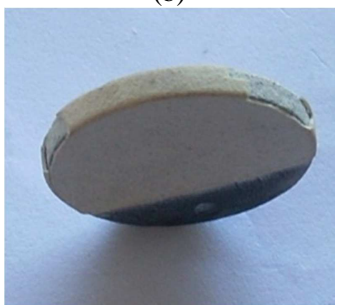

(d)

Fig. 1. Macrostructure analysis on specimen as received (a) and specimen after thermal fatigue at $900 \mathrm{oC}$ (b) 2 cycles, (c) 6 cycles, (d) 42 cycles

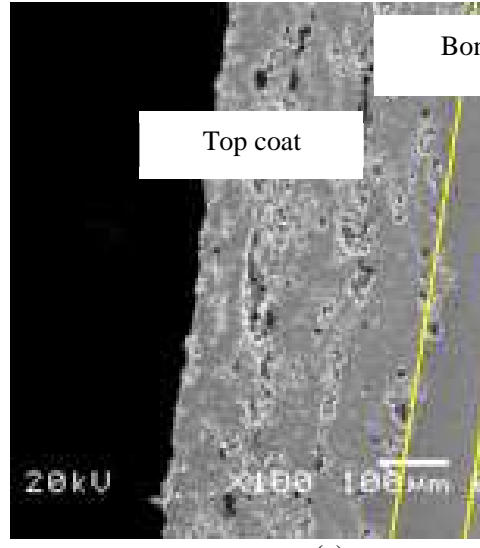

(a)

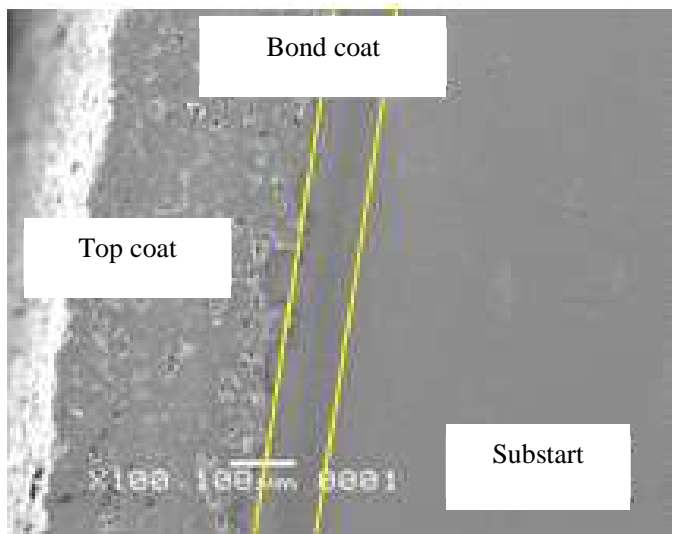

(b)

Fig. 2. Electron microscope analysis on specimen (a) as-received; (b) after thermal fatigue 42 cycles 
IPTEK, The Journal for Technology and Science, Vol. 21, No. 4, November 2010

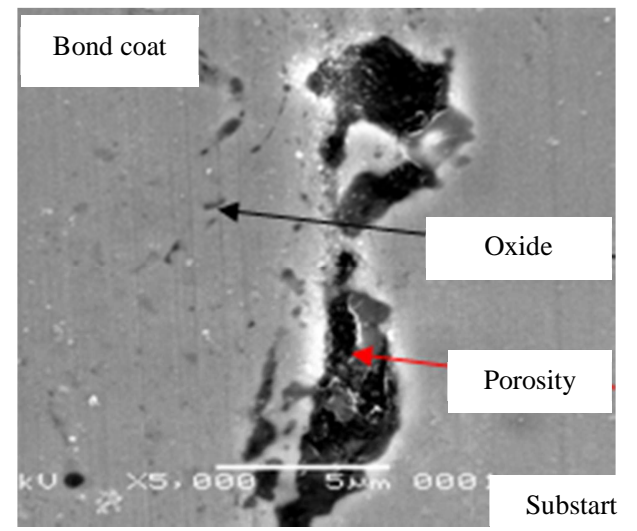

Fig. 3. Electron microscope analysis on as received specimen

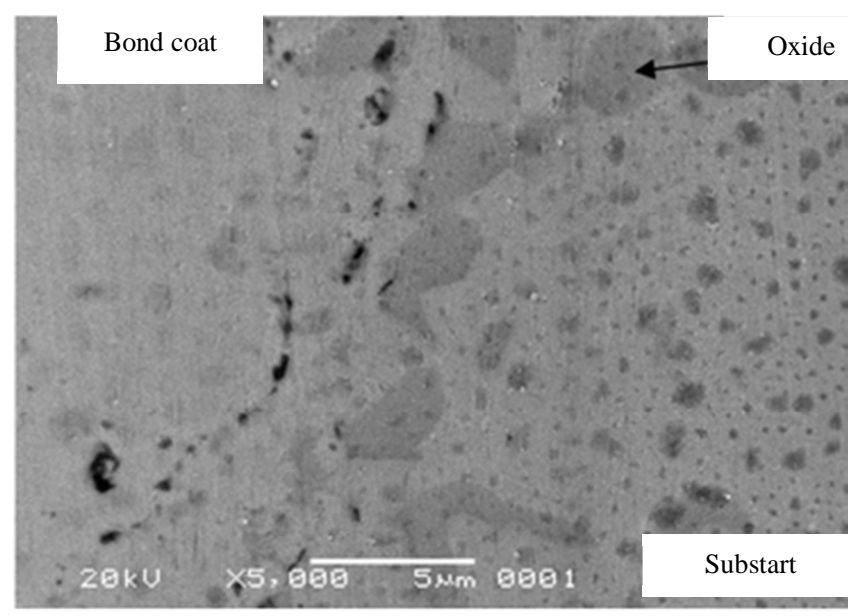

Fig. 4. Electron microscope analysis on specimen after thermal fatigue at $900^{\circ} \mathrm{C}-42$ cycle. It is shown dark area and bright area indicating the difference on morphology

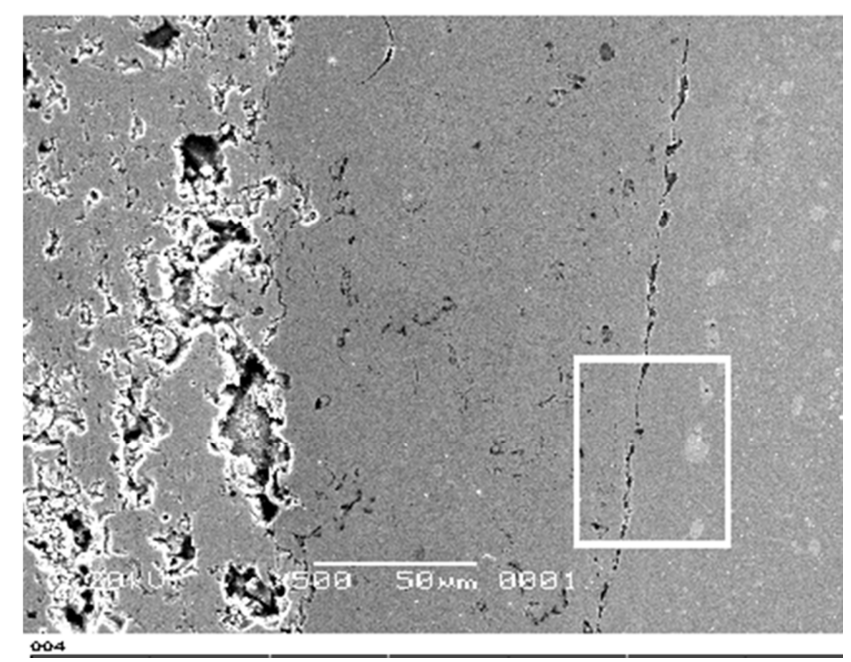

Fig. 5. SEM/EDX analysis on thermal fatigue specimen, this analysis was done to observe element diffusion along the interface 
IPTEK, The Journal for Technology and Science, Vol. 21, No. 4, November 2010

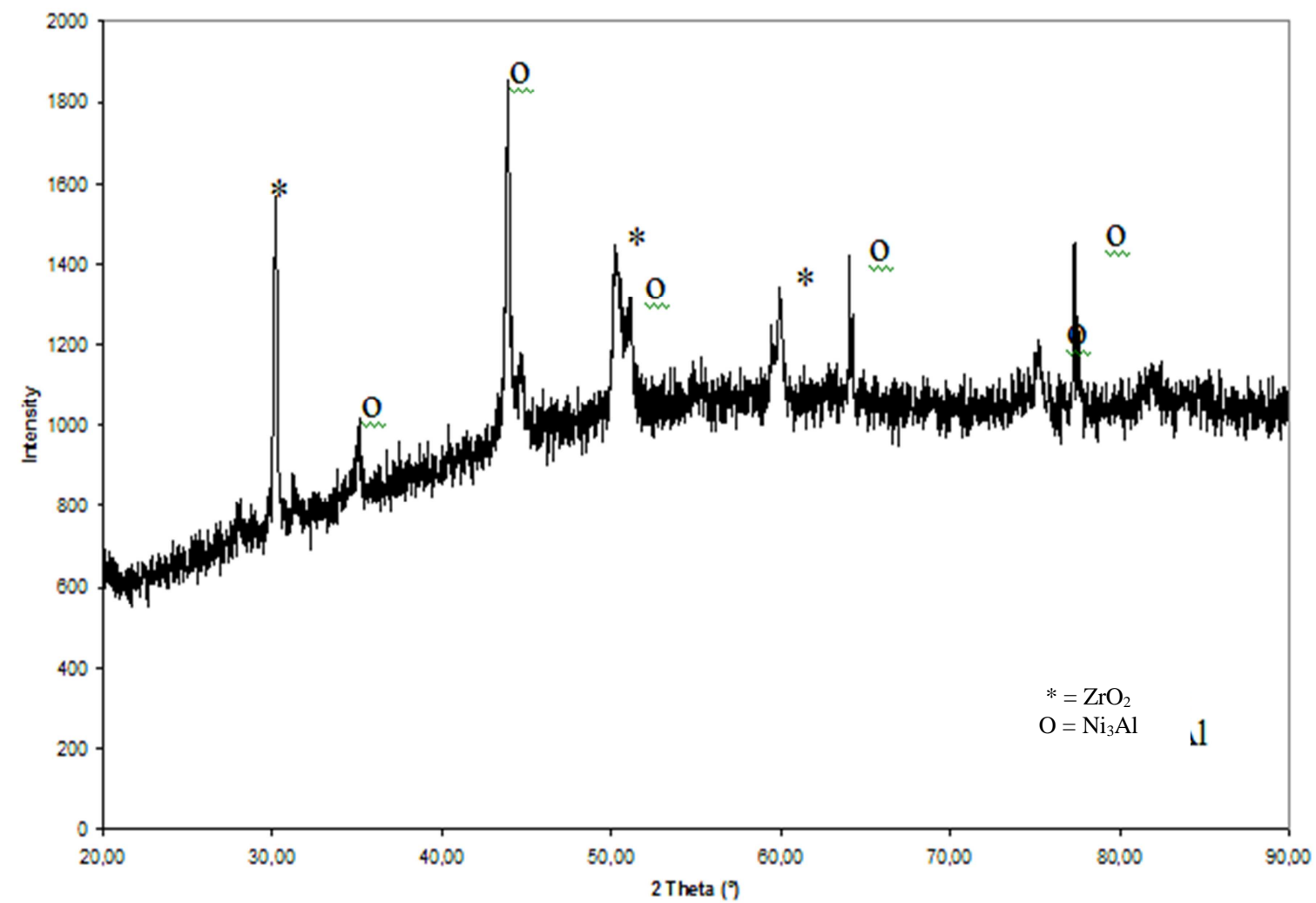

(a)

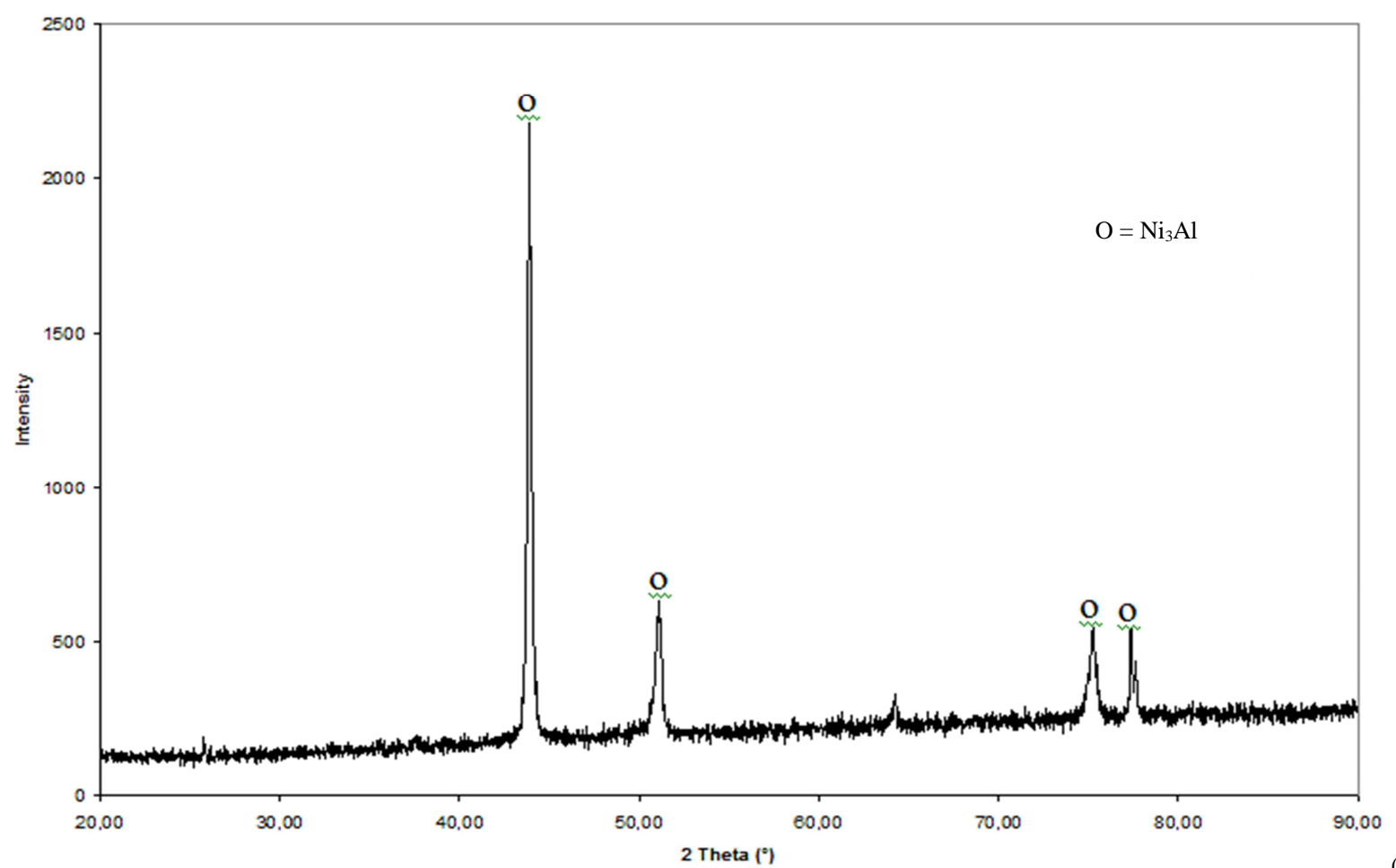

(b)

Fig. 6. X-ray diffraction analysis on (a) as-received, (b) after thermal fatigue at $900^{\circ} \mathrm{C}-42$ cycles. On as-received specimen indicate zirconia and $\mathrm{Ni}_{3} \mathrm{Al}$ phases. Zirconia is remaining phase of top coat layer and $\mathrm{Ni}_{3} \mathrm{Al}$ is new phase that is formed by diffusion of elements bond coat and substrate 
IPTEK, The Journal for Technology and Science, Vol. 21, No. 4, November 2010 